\title{
Yoga for Gender-Based Empowerment: A New Approach in Employee Wellness
}

\section{Shikha Vyas-Doorgapersad}

\author{
J. Surujlal \\ Vaal Traingle Campus, North-West University
}

Doi:10.5901/mjss.2014.v5n13p268

\section{Abstract}

The well-being of employees has become an important issue in a competitive market within organisations. This is influenced in part by the fact that modern man is much more alert to his/her rights and more intent on leading a balanced life; increasingly seeking for a greater balance between work, leisure and family life. In its quest to gain a competitive edge in its industry, an organisation needs to consider the well-being of its employees. Among the different strategies that organisations use to ensure the well-being of its employees is yoga. Yoga has gained increased attention and popularity worldwide as a new means for improved physical and mental health. It has now become an integral part of many global organisations to positively alter the behaviour patterns of employees who experience high stress levels. Although yoga has been getting widespread acclaims, the relative roles of yoga on employee well-being has not being studied comprehensively. The purpose of this study was therefore to explore relationship between the implementation of gender-based yoga and enhancement of employees' wellness for improved productivity. In order to obtain relevant data, qualitative methods were utilized. Based on the findings implications for further studies are made.

Keywords: Yoga, well-being, employees, productivity,

\section{Introduction}

Yoga, an almost 26,000 years old Indian-based spiritual tradition can be understood through varied traditionally-induced meanings. The term originated from the Sanskrit word 'Yuj' meaning unity/union. On one hand, yoga can be considered as a connection between the physical and cosmic-consciousness. On the other hand, yoga can be vital for aligning body, mind, spirit and soul. This yogic configuration can be achieved through following five paths (compiled from Narasimhan and Prasad, 2012: 2): Jnana Yoga or Jnana Marga (path of knowledge), the Yoga of wisdom; Bhakti Yoga (path of devotion), the Yoga of devotion; Karma Yoga (path of self-less action), the path of action of selfless service; Raja Yoga or Ashtanga yoga (eight-fold yoga), the royal or psychological which involves the mind; and Mantra, Naada yoga, the world of sound is also seen as a manifestation of Supreme Being.

Ban and Tomescu (2008: 239) state that "[w]ellness is generally used to mean a healthy balance of the mind-body and spirit that results in an overall feeling of well-being. It has been used in the context of alternative medicine since Halbert Dunn began using the phrase high-level wellness in the fifties, based on a series of lectures at a Unitarian Universalist Church in Arlington, Virginia, in the United States. The modern concept of wellness did not, however, become popular until the 1970's". Wellness programmes can be as simple and inexpensive as providing information about stop-smoking clinics and weight-loss programmes or as comprehensive and expensive as providing professional health screening and fitness facilities (Gijana, 2011). Furthermore, organisations can promote wellness by incorporating employee wellness into the overall strategy and the culture of the organisation.

Gender is conceptually defined by various scholars and academics (Rubin, 1975; Molyneux 1985; Moser, 1993; Cherry, 2013) as varied attributes linking to feminine and masculine aspects, namely differentiated roles and responsibilities, identity, attitudes, behaviour patterns, needs and requirements. In this context, "both women and men deserve equal respect, opportunities and appreciation in the society" (Reddy, 2006: 28; Quirk, 2013: 1), and hence demand physical, emotional and mental empowerment. The current study therefore employs the "empowerment approach" (Govender \& Vyas-Doorgapersad, 2013; Vyas-Doorgapersad, 2013) as a theoretical scaffold for the study.

The reasons to follow yogic paths are to bring balance within and between body, mind and soul; enhance concentration, create focus, remove negative patterns of behaviour, develop clarity in thinking, improve inner strength, reduce stress and induce self-healing. These imperative benefits are vital for women and men equally who experience physical, emotional, and psychological stresses complemented with pressurized demands of work. The study introduces the utility of yoga for employee wellness in the South African employment sector from a gender perspective, emphasizing its significance for empowerment. 


\section{Employee Wellness: An Overview}

\subsection{Stress and Employee Wellness}

According to a research conducted by Van Zyl (2002), a huge percentage of the population suffers from stress. This is reflected in the high figures of Coloureds (34,7\%), Whites and Asians (38,1\%) and Black (35\%) South Africans who suffer from high stress levels. This concern can be supported with the views of Eriksson (2012) of the human resources effectiveness group emphasizing that South Africans experience abnormally high levels of stress in the workplace compared to the rest of the world. There are various contributing factors for stress. They could be personal (divorce, family problems) or professional (work-related demands, high benchmarks), with consequences such as absenteeism, suicidal attitude, verbal abuse, conflict, depression, low esteem, less productivity and anger. The stress levels themselves can reflect "an adverse relationship between, situational analysis of the climate in the organization and employee productivity; absenteeism, sick leaves and financial implications; high chronic health conditions resulting in the need for an integrated focus on the wellness of the employees" (North-West University, 2006: 2). The stress is not only visible in the public and private labour markets. Research (Barkhuizen \& Rothmann, 2008) suggests that educational sector employees also experience occupational stress due to an imbalance between work (evening lectures) and personal life, lack of communication between colleagues, differentiated salary scales and promotion aspirations. The South African employment sector is in dire need of incorporating strategies to assist employees coping with stress levels. The current study suggests that an Employee Wellness Programme needs to incorporate yoga as an alternative therapy complementing good diet, exercise, healthy eating habits and daily meditation practices.

\subsection{Yoga and Employee Wellness}

The significance of yoga has been realized by some of the companies in South Africa. Companies such as First National Bank, Investec, Old Mutual, Regenesys and Nandos, are some of the organizations that have incorporated yoga in their employee wellness programmes, whereby the concept corporate yoga emerged. New concepts and designations are emerging with innovative ideas to cope with the stress at work-place. Martin Combrinck who holds positions as a Chief Happiness Officer (CHO)] at Founder at Laughter for Africa, also a CEO and Founder at Sanga Wellness, and an Educator at Ananda Sanga Educational Institute, is popularly known as 'The Corporate Yogi' in Cape Town, offers corporate wellness strategies to companies incorporating yoga modalities. The essence is spreading at the macro level, whereby the Employee Assistance Professionals Association of South Africa (EAPA-SA)'s 2012 National Conference (Somerset West, Cape Town) experienced an early morning Yoga and Meditation Bootcamp. This is an indication that there is an awareness of the value of aligning these alternate healing modalities in the Employee Wellness programmes for improved health, enhanced mental status with better focus, concentration and clarity. This may ultimately lead to an outcome of improving productivity at the work-place. This event was organized by a company called Enov8, established to plan events/conferences/seminars on behalf of varied clients, allowing them to enjoy stress-free events. This nature of assistance allows clients to utilize their time in networking, instead of dealing with organizing issues that result in stress.

\subsection{Gender and Yoga}

At the spiritual level, yoga incorporates the gender aspect in the form of 'masculine' [the yang] and 'feminine' [the yin] characters that everybody possesses, but not always in a balanced manner. On the materialistic dimensional plane, [male and female] employees demand varied yogic healings to cope with stress. The characteristics of yin are cold, passive, inside, solid, slow, right and dim. The yang qualities are light, hot, active, outside, hollow, rapid and bright. The energies of yin and yang need to be balanced, otherwise the transition can be devastating - a heart attack could be the balancing force applied to us. These imbalances are often referred to as either a 'deficiency' or an 'excess'. We can have an excess of yin or a yin deficiency; we can have an excess of yang or a yang deficiency. The solution is to apply the opposite energy to control the excess or deficiency" (yinyoga.com, 2014: 2). Yoga therefore has to offer assorted yoga facets applicable to males (enhancing yin in them) and female (strengthening yang in them) for proper emotional, physical, psychological, and mental well-being. This balance is also vital to comprehend the gender-based requirements at professional and personal levels, hence avoiding conflict-based stress with improved harmony-based understanding.

Very little research literature or studies exist in the South African context that examine the role that yoga plays both in wellness in an organization as well as its contribution to gender empowerment. Hence, the purpose of this study was to explore corporate, academic and government organisation employees' perceptions of yoga as a component of wellness programmes. 


\section{Research Methodology}

A comprehensive literature study was undertaken to explore the influence of yoga on employee wellness in the professional workplace. A literature review is defined as "the use of ideas in the literature to justify the particular approach to the topic, the selection of methods, and demonstration that this research contributes something new" (Levy \& Ellis, 2006: 2). Moreover, it is considered as a "critical analysis of a segment of a published body of knowledge through summary, classification, and comparison of prior research studies, reviews of literature and theoretical articles" (Duke University, 2010: 1). In addition, a qualitative research approach was employed to gather data from employees of selected organizations that have incorporated and implemented yoga in their employee wellness programmes. By its very nature, qualitative research is a value-laden inquiry. It investigates the reality of participants as they experience it by using narrations and descriptions of their real life experiences (Repko, 2008). It can be deduced that "qualitative research typically studies people or systems by interacting with and observing the participants in their natural environment and focusing on their meanings and interpretations" (Ntuli, 2012). The aim of the qualitative research, therefore, is "to describe the meanings and challenges experienced as result of utilising and implementing certain programs, practices or processes" (Mertens, 2010:225).

In this study open-ended questions were employed to gather responses from the target population.

\subsection{Sample}

Due to the fact that yoga has been embraced by a limited number of organisations, the probability to obtain responses in a country-specific restrictive boundary was difficult. The principal researcher utilized web sources to obtain the names of organizations/professionals who were involved in practicing and teaching yoga. The sample therefore comprises those individuals who accepted the request for participation (not all contacts were reachable in a sense that: some contact details had changed, some returned with error, some did not respond at all). Due to the time constraints, a one-month duration was considered sufficient to collect the data. During this time, three male and nineteen female practitioners submitted their responses. In total, twenty-two responses were received from the KwaZulu Natal, Cape Town and Gauteng provinces in South Africa.

\subsection{Instrument and procedure}

An interview schedule was developed comprising issues such as previous experience/knowledge with yoga; reasons for the use of alternative therapy; behavioural/attitudinal changes; work productivity; and wellness changes. Standardization was ensured by administering the same set of questions to all respondents. Follow-ups were done if responses received were unclear.

Due to the geographical challenge associated with the study (the organizations considered are national institutions and are situated outside the boundaries of authors' place of work), the digitized manner was utilized in receiving responses. In this case, interview questionnaires were emailed to the respondents requesting them to respond via email.

\subsection{Data analysis}

Once all the responses were received, the data were captured on a spreadsheet so that a global view of the responses was available to the researchers. The data was then content-analysed. An inductive approach followed the guidelines suggested by Cote, Salmela and Russell (1995) was used to analyse the content of the data. Similar ideas were clustered and specific themes allocated to them. Three main issues as specified by Srivastava and Hopwood (2009), namely: what the data was 'saying', what the researchers wanted to know and the dialectical relationship between what the data was telling them and what they wanted to know" provided direction in analysing the data.

\subsection{Ethical considerations}

Research ethics "concern the responsibility of researchers to be honest and respectful to all research participants. This means providing research participants with complete information and their role in the research. The information provided to participants should enable them to participate or not. This also implies that before they take part in research the to-be respondents should understand the nature and value of research they are to engage into (Gravetter \& Forzano, 2006). Respondents were informed regarding research ethics and were ensured that their responses will be confidential and they would remain anonymous at all times.. Participants were also informed that their participation was voluntary, hence 
participation in the study implied their consent to participate.

\section{Results and Discussion}

According to Surujlal (2013) the description and interpretation of the data in some qualitative studies are closely linked. Gustafsson, Hassmén, Kenttä and Johansson (2008) argue that such an approach prevents the repetition of explanations. Hence the results and discussion are merged.

The semi-structured interview schedule comprised two sections. The first section sought demographic information of the respondents. The results are provided in Table 1.

Table 1: Demographic profile of respondents

\begin{tabular}{|c|c|c|c|c|}
\hline Criteria & \multicolumn{4}{|c|}{ Responses } \\
\hline Gendern & \multicolumn{2}{|c|}{$\begin{array}{c}\text { Male } \\
3\end{array}$} & \multicolumn{2}{|c|}{$\begin{array}{c}\text { Female } \\
19\end{array}$} \\
\hline Age & \multicolumn{2}{|c|}{ Between $44-45$ years } & \multicolumn{2}{|c|}{ Between 34-71 years } \\
\hline Previous experience with yogan & $\begin{array}{c}\text { Yes } \\
3 \\
\end{array}$ & $\begin{array}{c}\text { No } \\
0\end{array}$ & $\begin{array}{c}\text { Yes } \\
15 \\
\end{array}$ & $\begin{array}{c}\text { No } \\
4\end{array}$ \\
\hline Prior knowledge with yogan & $\begin{array}{c}\text { Yes } \\
3\end{array}$ & $\begin{array}{c}\text { No } \\
0\end{array}$ & $\begin{array}{c}\text { Yes } \\
12\end{array}$ & $\begin{array}{c}\text { No } \\
7\end{array}$ \\
\hline Years of practicing yoga & \multicolumn{2}{|c|}{ Between $3-25$ years } & \multicolumn{2}{|c|}{ Between 1- 41 years } \\
\hline
\end{tabular}

The respondents belonged to a diverse professional arena, varying from education, management, banking, IT, interior designing and animal behaviourist. Some are health and yoga practitioners/wellness coaches offering yoga-based guidance to corporate professionals. These respondents were actively engaged in diverse sport/recreation activities before joining yoga. These activities include varied forms of sports, athletics, drama/dance, tai chi, gardening, and fitness training. Although respondents believed in an active lifestyle, they opted for yoga as an alternative due to its health, emotional, and spiritual benefits. Yoga, in this case, complemented their lifestyle. In terms of gender, there were more female practising yoga with their period of engagement ranging from one to 41 years. Though some female respondents did not have any prior knowledge of yoga, once aware, it has become essential aspect of their everyday's life. Although very few male responded, they were all equipped with knowledge of yoga. This is a positive sign towards gender-based and gender-balanced approach towards yoga. An elaboration of responses received under section two of the interview schedule is reflected in Table 2. The responses are summarized maintaining the authenticity of [personal] expression.

Table 2: Qualitative themes and responses

\begin{tabular}{|c|c|c|}
\hline Theme & Responses from male & Responses from female \\
\hline $\begin{array}{l}\text { Reasons for use of } \\
\text { alternative therapy }\end{array}$ & $\begin{array}{l}\text { Yoga builds up physical, emotional strength in a balanced } \\
\text { way; it is a good therapy for body and mind. }\end{array}$ & $\begin{array}{l}\text { Yoga is a complete tool for health, emotional } \\
\text { and spiritual well-being. }\end{array}$ \\
\hline Behaviour changes & $\begin{array}{l}\text { Positive. One becomes more tolerant, objective, } \\
\text { confident. } \\
\text { Negative. It was difficult in the beginning, and more pain } \\
\text { but this time around 'good pain'. But the most profound } \\
\text { was the quietening of the mind and then slowly changing } \\
\text { from a driven individual mentally to one who is calm and } \\
\text { serene and on top of anything that is thrown my way. The } \\
\text { long terms is the flexibility and the strength, }\end{array}$ & $\begin{array}{l}\text { Positive. One develops more awareness } \\
\text { towards personal health, becomes more rational } \\
\text { in professional approach, develop good } \\
\text { relationships at workplace. } \\
\text { Negative. I still experience a degree of pain but } \\
\text { not debilitating pain just a reminder that I am } \\
\text { alive and ageing and also that some of the } \\
\text { damage done is irreversible. }\end{array}$ \\
\hline $\begin{array}{l}\text { Attitude to the therapy } \\
\text { since its first use }\end{array}$ & $\begin{array}{l}\text { Strong. Yoga helps to focus, concentrate, more adaptive } \\
\text { to surroundings. }\end{array}$ & $\begin{array}{l}\text { Most definite. Yoga is calming, integrates left } \\
\text { and right brain functions, teach self-acceptance } \\
\text { and humility. }\end{array}$ \\
\hline Relationship with others & One becomes more tolerant, objective, rational, logical. & $\begin{array}{l}\text { One becomes more calmer, less stressed, } \\
\text { dissolve anger, more happier, detached from } \\
\text { workplace conflicts. }\end{array}$ \\
\hline Work productivity & Higher productivity levels. & More productive. \\
\hline $\begin{array}{l}\text { Physical, emotional, } \\
\text { health changes }\end{array}$ & All aspects improved. & Healing to all aspects of a personality. \\
\hline
\end{tabular}




\begin{tabular}{|l|l|l|}
\hline $\begin{array}{l}\text { Reactions of others } \\
\text { towards yoga }\end{array}$ & People realized they 'should' do yoga. Positive effect. & $\begin{array}{l}\text { People realized that yoga has an impact on } \\
\text { lifestyle, attitude, fitness, and overall well-being. } \\
\text { Positive effect. }\end{array}$ \\
\hline Recommendations & $\begin{array}{l}\text { Organizations 'should' offer yoga. Yoga reduces } \\
\text { absenteeism due to stress related illnesses }\end{array}$ & $\begin{array}{l}\text { HR/strategic decision-makers must promote } \\
\text { yoga as the trickle down factor influences all } \\
\text { employees. Yoga strengthens core beliefs with } \\
\text { improved ethics. }\end{array}$ \\
\hline
\end{tabular}

Reference to the results of the qualitative study reflects that the positive benefits outweigh the negative consequences of participating in Yoga. All respondents agreed to the fact that yoga can play an instrumental role in employee wellness as it contributes to decreased levels of health-related illnesses, promotes emotional well-being and develops enthusiasm required for enhanced productivity at the workplace. This finding is supported by Wojcik (2011) who reported that employees are realizing that a psychologically healthy workplace enhances organizational performance and productivity.

From the responses it evident that respondents perceived yoga to contribute to emotional strength. Srinivasan (2013) posits that emotions are the motivating factors of one's life. They can be productive, empowering and creative, or they can be addictive, negative and abusive. One can therefore deduce from the afore-mentioned that increased emotional and mental strength of employees, if properly directed, can result in positive outcomes for the organisation. Srinivasen (2008) opine that through yoga one is able to master one's emotional strength which will improve the ability to concentrate, focus and remove distractions. It may therefore be implied that more focussed employees in an organisation are likely to be more efficient and productive.

Respondents also perceived that their practice of yoga contibuted to their lower levels of stress. This finding is consistent with findings of previous research. According to Kitamura (2013) yoga and meditation plays a significant role in reducing stress and stress-induced conditions such as hypertension and depression as well as the aging process. Campbell and Moore (2004) found that subjects in their study who were subjected to six weeks of yoga practice for stress had, on average, lower levels of depression, anxiety and stress symptoms than before the beginning of the study.

A few respondents also identified reduced absenteeism as a positive benefit of practising yoga in the workplace. According to Hope (2013) stress was reported to be the leading cause of absenteeism in the workplace. Hence it stands to reason that if practising yoga contributes to lower leves of stress then it is likely that absenteeism will be reduced.

Increased levels of tolerance were also identified as a positive benefit of practising yoga. This finding is consistent with the view of Zarthostimanesh (2014). According to Zarthostimanesh (2012) tolerance increases and becomes a virtue not if one tolerates more but if it synthesizes itself with other qualities like patience (titiksha), forbearance (sahana shakti), peacefulness, calmness (shanta guna), forgiveness (kshama), knowing, determination, and compassion. This implies that more tolerant employees are likely to have better relationships with others in the organisation thereby contributing to a more harmonious workplace.

Yoga is significant to widen focused approach with a team-spirit attitude required to create a harmonious working environment. The responses correspond with the empowerment approach emphasizing that both men and women deserve equal appreciation (Govender \& Vyas-Doorgapersad, 2013). Yoga can be considered as a contributing factor under employee wellness programmes as it reduces levels of stress avoiding absenteeism, hence improving organizational productivity. The responses confirm the reasons to follow yogic path in order to bring balance between professional and personal aspects of life.

\section{Limitations and Implications for Further Research}

Although the findings of the study provide evidence of the perceived benefits of practising yoga, there were significant limiting factors such as the lack of diversity of participants and the small sample size. As such, the study results cannot be generalised to the greater population. Reliance was on data from participants who were reasonably well acquainted with the practice of yoga, hence it may be possible that their views are biased in favour of yoga. It is anticipated that the current study could precipitate further interest and research into the phenomenon. Future research could, therefore, explore the views of both yoga practitioners and non-practitioners using a larger sample size. This may perhaps portray a more balanced picture of the perceptions of yoga.

\section{Conclusion}

Based on varied responses received, the article deduces some of the valuable thoughts and concludes that yoga is an art, science and philosophy that has been around for millennia. In many shapes and forms cultures have incorporated it 
into their own. Modern science consistently tries to prove or disapprove its benefits, but undeniably it will sustain the test of time as a practice that benefits people mentally, spiritually and physically. It adds a spiritual dimension to any existing religious beliefs, while adding a physical dimension to any existing sporting activity. As a mutually beneficial practice it also helps people/employees at workplace to free their minds and take responsibility for their own lives, established professional goals, and overall well-being.

\section{References}

Barkhuizen, N. \& Rothmann, S. (2008). Occupational stress of academic staff in South African higher education institutions. SA Journal of Psychology, 28, 321-336.

Ban, O. \& Tomescu, A.M. (2008). Study regarding the opportunity of transformation a spa center into a wellness center. Management of the Product Life Cycle and Competitiveness on the Tourist Market, 239-246.

Cherry, K. (2013). What is gender? Available at http://psychology.about.com/od/gindex/g/gender.htm. Accessed on 2013/08/21.

Cote, J., Salmela, J.H., \& Russell, S.J. (1995). The knowledge of high-performance gymnastic coaches: Methodological framework. The Sport Psychologist, 9, 65-75.

Duke University. (2010). Literature Review. Available at http://uwp.duke.edu. Accessed on 2010/05/12.

Eriksson, V. (2012). 'Billions lost' to workplace stress in SA. Available at http://www.bizcommunity.com/Article/196/336/70038.html. Accessed on 2014/05/12.

Gijana, A.P. (2011). Assessing challenges in public appointments and recruitment processes in Chris Hani District Municipality: a case study of human resource department in Lukhanji Local Municipality (2008 -2010). Mini-Dissertation. University of Fort Hare: Department of Public Administration.

Govender, S.D. \& Vyas-Doorgaersad, S. (2013). The implementation of gender equality policies in achieving millennium development goal three in the Sedibeng District Municipality. Journal of Public Administration. 8 (1), 105-117.

Gravetter, F.J. \& Forzano, L.B. (2006). Research Methods for the Behavioral Sciences. (2nd ed.). Mason, OH: Thompson.

Gustafsson, H., Hassmén, P., Kenttä, G., \& Johansson, M. (2008). A qualitative analysis of burnout in elite Swedish athletes. Psychology of Sport and Exercise, 9(6), 800-816.

Hope, C. (2013). One in three absences at work due to anxiety and stress, official Government survey finds. Available at: http://www.telegraph.co.uk/health/healthnews/10143915/One-in-three-absences-at-work-due-to-anxiety-and-stress-officialGovernment-survey-finds.html. Accessed on 2014/04/14.

Levy, Y. \& Ellis, T.J. (2006). A systems approach to conduct an effective literature review in support of information systems research. Informing Science Journal, Available at http://inform.nu/Articles/Vol9/N9p181-212Levy99.pdf. Accessed on 2012/07/25.

Mertens, DM. (2010). Transformative Mixed Method Research - Qualitative Inquiry. Washington DC: Gallaudet University.

Molyneux, M.(1985). Mobilization without emancipation? Women's Interests, the State, and Revolution in Nicaragua. Feminist Studies. $11(2), 227-254$

Moser, C. O. N. (1989). Gender Planning in the Third World: Meeting Practical and Strategic Needs. World Development. 17(1), 17991825.

Narasimhan, A. \& Prasad, M.G. (2012). The role of Yoga-Asanas in Mind-body Harmony. Available at http://www.durvasula.com /Taranga/yogasana.pdf. Accessed on 2014/01/24.

North-West University. (2006). Employee Wellness Programme Draft, 2006. Potschefstroom: NWU.

Ntuli, N.M. (2012).The impact of a performance management and development system on employee performance for enhanced service delivery at Sedibeng District Municipality.Vanderbijpark: Vaal Triangle Campus (North-West University): un-published Minidissertation.

Quirk, V. (2013). Personal google page: March 08, 2013. Available at https://plus.google.com/105849455450101421772/posts. Accessed on 2013/03/08.

Srivastava, P. \& Hopwood, N. (2009). A Practical Iterative Framework for Qualitative Data Analysis. International Journal of Qualitative Methods, 8(1), 76-84.

Reddy, P.S. (2006). A Strategic Framework for Gender Equality within the Public Service (2006-2015): a consultation document. Pretoria: Department of Public Service and Administration.

Repko, A.F. (2008). Interdisciplinary Research: Process and Theory. London: Sage.

Rubin, G. (1975). The Traffic in Women: Notes on the 'Political Economy' of Sex. In R. Reiter (ed.), Toward an Anthropology of Women, New York: Monthly Review Press. 157-210.

Srinivasen (2013). Building Emotional Strength with Raja Yoga- Part 3 by Srinivasan. Available at: http://yogacamp.wordpress.com/2013 112/30/building-emotional-strength-with-raja-yoga-part-3-by-srinivasan/. Accessed on 2014/04/14.

Surujlal, J. (2013). Appraising coach performance: A qualitative analysis of coaches' perceptions. African Journal for Physical, Health Education, Recreation and Dance, 19(1), 30-43.

Van Zyl, E.S. (2002). The measurement of work stress within South African companies: a luxury or necessity. SA Journal of Industrial Psychology, 2002, 28(3), 26-31.

Vyas-Doorgapersad, (2013). Domestic water resource management: a shift from gender-biased to gender-based approach. Administratio Publica, 21 (2), 4-20.

Wojcik, E. (2011). Postgrad growth area: Designing workplace wellness programs. Available at: http://www.apa.org/gradpsych/2011/11 
/postgrad.aspx. Accessed on 2014/04/21.yinyoga.com. (2014). Yin and Yang. Available at http://www.yinyoga.com /ys1_0.1_yin_yang.php. Date accessed 24/2/2014.

Zarthoshtimanesh, Z. (2012). Developing tolerance through yoga. Available at https:/liynaus.org/yoga-samachar/fall-2011winter2012/developing-tolerance-through-yoga. Accessed on 2014/04/14. 